las reducidas dimensiones de su patrimonio raíz. Esa falta se contrarrestaba con una excesiva dependencia de las conmutaciones de los hermanos, que provocó la crisis económica de la fraternidad a comienzos del XIX, tanto por la escasez de vocaciones como por el incremento de las deudas entre los hermanos. Por último, los gastos de la fraternidad remarcan las dimensiones devocionales y funerarias de la V.O.T. leonesa en detrimento de las asistenciales.
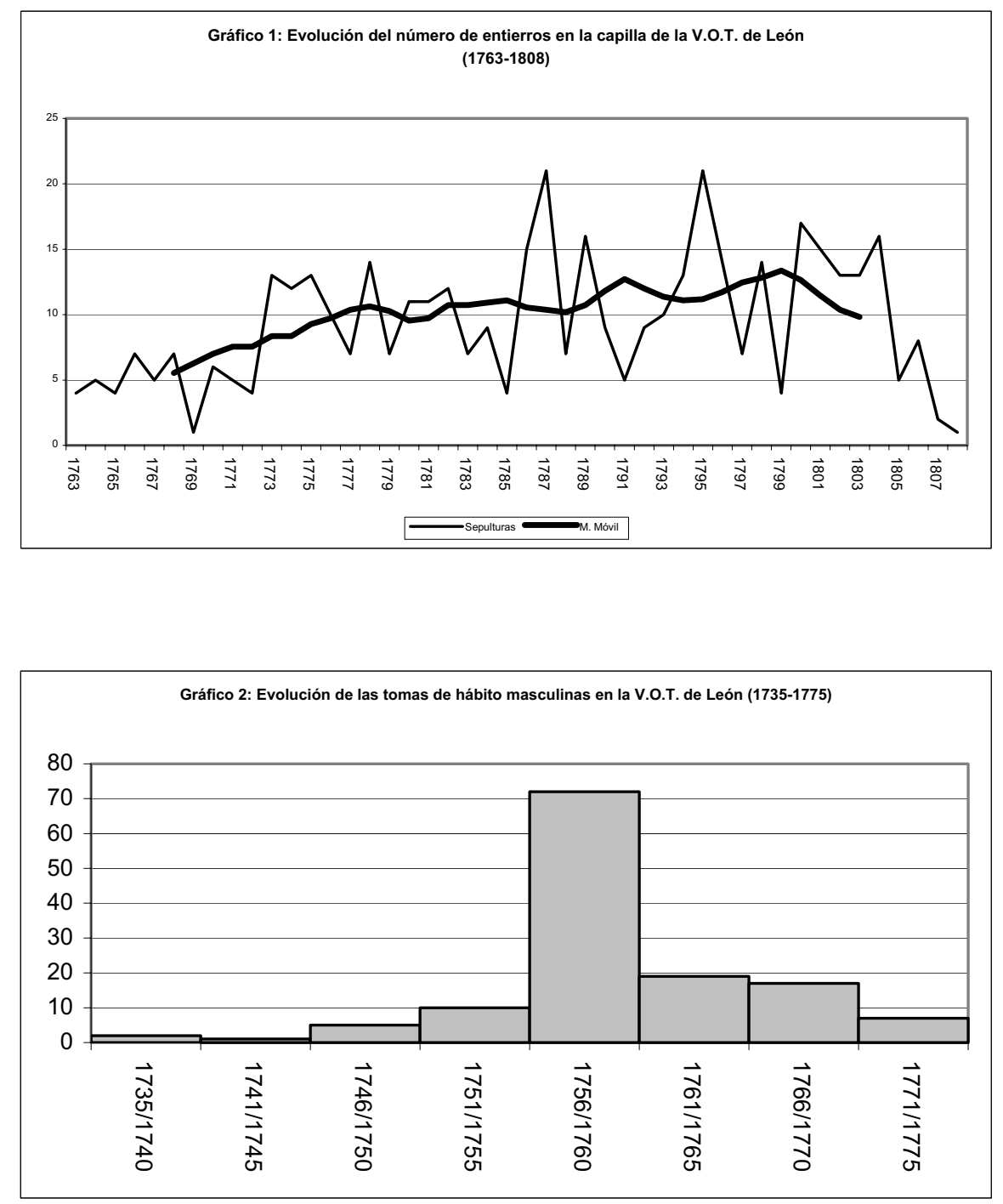
Alfredo Martín García

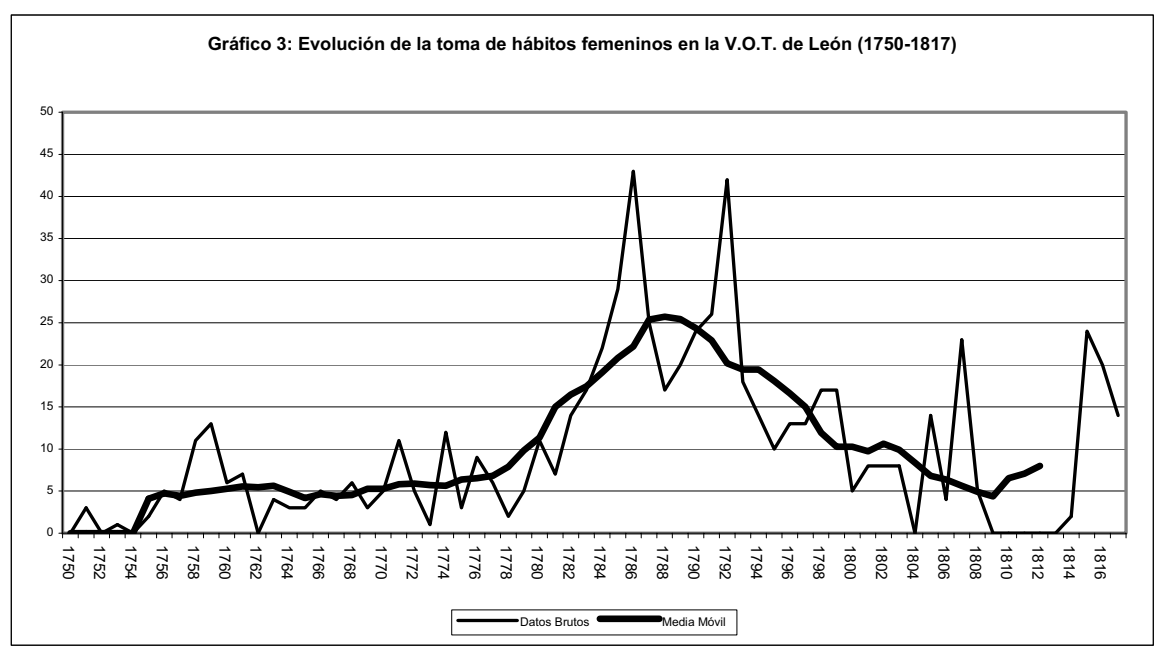




\title{
LOS MOVIMIENTOS SOCIALES EN LA PROVINCIA DE LEÓN DURANTE LA ETAPA INICIAL DE LA TRANSICIÓN: 1975-1977
}

\author{
David MARTÍNEZ PÉREZ \\ Universidad de León
}

\begin{abstract}
RESUMEN: Los movimientos sociales fueron fundamentales en la Transición, ya que pugnaron con los proyectos continuistas de la dictadura para lograr el establecimiento de la democracia en España. Así ocurrió también en León mediante las formaciones regionalistas, los grupos estudiantiles, las asociaciones de vecinos y las organizaciones feministas.

PALABRAS CLAVE: movimientos sociales, Transición, León.

ABSTRACT: The social movements were fundamental in the Transition, since they struggled with the projects continuistas of the dictatorship to achieve the establishment of the democracy in Spain. It happened this way also in León by means of the formations regionalistas, the student groups, the associations of neighbors and the feminist organizations.
\end{abstract}

KEY WORDS: social movements, Transition, León.

\section{INTRODUCCIÓN.}

\section{a. Definición y características de los movimientos sociales:}

Para profundizar en las características de los movimientos sociales es preciso saber que se caracterizan por ser "[...] la forma de "activación" de la sociedad por la cual los grupos de ciudadanos, reunidos en un proceso de identificación, promueven la transformación del orden social" ". Sin embargo, esta definición no reseña una característica tan destacable de los movimientos sociales como la estructura de las oportunidades políticas, que Tarrow resume en una serie de "[...] dimensiones consistentes -aunque no necesariamente formales, permanentes o

\footnotetext{
${ }^{1}$ Revilla Blanco, M. (1994). «El concepto de movimiento social: acción, identidad y sentido». Zona Abierta, p. 203.
} 
nacionales- del entorno político, que fomentan o desincentivan la acción colectiva entre la gente" ${ }^{2}$.

De esta forma nos encontramos con un cúmulo de "[...] acciones realizadas por un conjunto de sujetos motivados por unos intereses comunes, que adoptan una forma de organización más o menos estructurada, y diseñan unas prácticas de movilización concretas, actuando en una estructura de oportunidad política que facilitará o dificultará la acción y condicionará sus posibilidades de influir en la articulación del poder" ${ }^{3}$.

\section{b. Los movimientos sociales en el franquismo y la Transición.}

Los movimientos sociales españoles surgieron en las décadas de los sesenta y setenta, de una forma diferente a los europeos, debido al "fuerte y desequilibrado" desarrollo económico de ese período, al marco político dictatorial opuesto al democrático europeo y al fuerte intervencionismo de las instituciones estatales.

De esta forma la lucha por el restablecimiento de la democracia, no sólo como sistema político, sino como forma de "modernización", se convirtió en el elemento central de la configuración de los movimientos sociales. Los partidos de la oposición se identificaron con muchas de la posiciones de estos grupos, las apoyaron, e incluso aprovecharon su legitimación y sus acciones. Por lo tanto, en este período inicial de la Transición democrática las movilizaciones estuvieron encabezadas por los movimientos sociales, aunque fueron utilizadas por la oposición para negociar el nuevo marco institucional y una vez conseguida la consolidación de la democracia se trató de desmovilizarlos, por temor a que se produjese una involución dictatorial ${ }^{4}$. Así estos grupos, debido a sus actuaciones del primer semestre de 1976, arrebataron la iniciativa política al Gobierno de Carlos Arias Navarro, lo que impidió la consolidación de su proyecto de tímido aperturismo, siendo sólo capaz de recuperarla Adolfo Suárez, cuando, tras las

2 TARROW, S. (1997). El poder en movimiento. Los movimientos sociales, la acción colectiva y la política. Madrid: Alianza Universidad, p. 49.

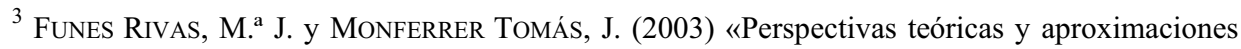
metodológicas al estudio de la participación» en Funes RIVAS, M. ${ }^{a}$ J. y ADELl ARGILÉs, R. (eds.) Movimientos sociales: cambio social y participación. Madrid: Universidad Nacional de Educación a Distancia, p. 23. Cursiva de los autores.

${ }^{4}$ AlONSO, L. E. (1991). «Los nuevos movimientos sociales y el hecho diferencial español: una interpretación» en VIDAL-BENEYTO, J. (ed.). España a debate II. La sociedad. Madrid: Tecnos, pp. 81 y 90 . 
elecciones del 15 de junio de 1977, el protagonismo pasó de los movimientos sociales a los partidos políticos.

Asimismo la Transición democrática española significó un cambio en la estructura de oportunidades políticas, que fue percibido por los movimientos sociales, puesto que la muerte del dictador, aunque no significó de forma inmediata la desaparición de las instituciones políticas que había dirigido, supuso la desaparición de su poder simbólico, es decir, comenzó a disminuir lentamente el terror creado por la represión franquista.

\section{c. El franquismo en la provincia de León.}

La dictadura franquista, tras la sublevación militar, estableció su control político en la provincia de León por medio de una enorme represión de los elementos contrarios. Su institucionalización estuvo basada en el fortalecimiento del poder de los gobernadores civiles, la constitución del Movimiento como organización política, la creación de la Organización Sindical y el apoyo de la Iglesia católica. La oposición antifranquista en León fue en todo momento débil, pero no se trató de una región caracterizada por su "paz social". En un primer momento destacó la guerrilla antifranquista, que se preocupó más por sobrevivir que por derribar la dictadura, no en vano tras la Segunda Guerra Mundial sus posibilidades reales se agotaron $^{5}$. En la mayor parte de la provincia, no será hasta la Transición cuando se produzca un renacimiento de la conflictividad laboral, apoyado por los movimientos sociales, en su intento de acabar con los últimos residuos del franquismo. No obstante, en las comarcas mineras pervivió esta rebeldía, ante las malas condiciones de vida y laborales, organizada a través de las frágiles estructuras del PCE y Comisiones Obreras, además de los grupos católicos como la Hermandad Obrera de Acción Católica (HOAC) ${ }^{6}$.

\section{d. Metodología y fuentes usadas.}

En la presente investigación se han tenido en cuenta tres niveles de análisis micro (individual), meso (grupal) y macro (sistémico) ${ }^{7}$.

5 Sobre la guerrilla antifranquista se debe consultar: SERRANO, S. (1986). La guerrilla antifranquista en León (1936-1951). Valladolid: Junta de Castilla y León.

${ }^{6}$ Rodríguez GonzÁlez, J. (2000). «La dictadura franquista» y Álvarez FernÁNDeZ, F. J. «La oposición a la dictadura» en CARANTOÑa Álvarez, F. (coord.). Historia de León. Edad Contemporánea. Vol. IV. León: Universidad de León, pp. 415-461.

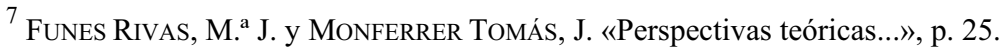


En el caso del micro se intentó conocer las motivaciones de los individuos que les indujeron a participar en los movimientos sociales. Para ello se utilizaron las fuentes orales mediante la entrevista semiestructurada de final abierto, ya que a partir de unas preguntas básicas se permite al entrevistado profundizar en unos aspectos $\mathrm{u}$ otros - siempre bajo la dirección tácita del entrevistador ${ }^{8}$. Una vez obtenido el testimonio oral fue confrontado con otras fuentes, de esta forma se precisó el grado de fiabilidad del entrevistado, la capacidad del entrevistador, la temática no tratada y si era preciso realizar una nueva sesión. El proceso de verificación usando otras fuentes u otros testimonios se tornará imprescindible para captar en su justa medida la fuente oral, no en vano esta aporta una nueva dimensión en la investigación.

El nivel meso o colectivo se centra en las organizaciones y las características de sus movilizaciones. Para conocerlo se utilizaron los documentos producidos por los movimientos sociales, tanto la propaganda constituida por octavillas o boletines, como los procedentes de su funcionamiento como libros de actas o resoluciones. Con respecto a las acciones realizadas fue utilizada la prensa, mediante las colecciones pertenecientes a La Hora Leonesa, Hoja del Lunes, y el Diario de León. La Hora Leonesa comenzó a publicarse el 1 de septiembre de 1975 y pervivió hasta el 16 de mayo de 1984. Surgió como continuación del periódico perteneciente a la prensa del Movimiento Proa. Por tanto su relación con el poder será constante, aunque tratará de diferenciarse del Diario de León al tratar de una forma más "social" la información.

El Diario de León fue fundado en 1906 como parte de la denominada prensa católica, debido a su vinculación al obispado leonés. Pese a que pretendía diferenciarse por su "catolicismo" frente al "gubernamentalismo" de La Hora Leonesa, en realidad ambos periódicos utilizaban las mismas fuentes. La Hoja del Lunes mantuvo una línea ecléctica más cercana a La Hora Leonesa $a^{9}$. A causa de las escasas diferencias entre estos periódicos locales se decidió utilizar El País, ya que se trataba del diario emblemático de la izquierda, el cual aportó una visión completamente distinta a la anterior. Por último, para profundizar en las actividades realizadas por las asociaciones vecinales se utilizó la revista Concejo, editada por el Ayuntamiento de León.

\footnotetext{
${ }^{8}$ Para comprender esta metodología: HAMMER, D. y WiLDAVSKY, A. (1990) «La entrevista semiestructurada de final abierto. Aproximación a una guía operativa». Historia y Fuente Oral, pp. $23-65$.

${ }^{9}$ La consulta de estos periódicos ha sido posible en las colecciones en CD-ROM de la Biblioteca Universitaria "San Isidoro" de la Universidad de León.
} 
Por último el nivel macro o sistémico que englobaría "[...] el sistema político, el social, el económico y el cultural" hizo preciso conocer la estructura de oportunidades políticas de la etapa inicial de la Transición cuyas características básicas pasarían por el "[...] tipo de Estado ante el que nos encontremos, las ideologías dominantes, la relación existente entre las elites políticas, o el grado de represión que ejerzan las autoridades ante las acciones de protesta. Desde el punto de vista del sistema social estudiaremos las características propias del tejido social en que se desarrollan las acciones"10. Para profundizar en esta categoría se utilizó la bibliografía y las fuentes anteriores.

\section{EL RESURGIMIENTO DE LAS ASOCIACIONES REGIO- NALISTAS.}

\section{a. La problemática regionalista leonesa en la Historia Contemporánea.}

El regionalismo, que reapareció durante la Transición en León, continuó fielmente las líneas esbozadas durante el primer tercio de siglo. Esto es, un regionalismo cultural que potenció una serie de características "comunes" a través de actos como el IX Centenario de los Fueros de León, celebrado en 1920, usado en contraposición al Centenario de las Comunidades Castellanas.

Este movimiento cultural "leonesista" actuó con el "castellanista" en numerosas ocasiones para defender posturas comunes, como por ejemplo en la Asamblea de Diputaciones de Burgos de 1918. Asimismo les unió el proteccionismo agrario y la defensa de la unidad de España, ambos ideales defendidos por las capas pudientes de la sociedad. Esta ideología conservadora se caracterizó por ser netamente defensiva, pues propugnó un ámbito administrativo de Castilla y León en contraposición al proyecto catalán de la Mancomunidad. Durante la Segunda República se profundizó en la idea de la alianza de las dos regiones, con la finalidad de tener la suficiente fuerza para oponerse a otros regionalismos, lo que se retomó durante la Transición, así como la vinculación de las instituciones regionalistas a las formaciones de la derecha ${ }^{11}$. Por supuesto durante la dictadura franquista esta problemática fue obviada.

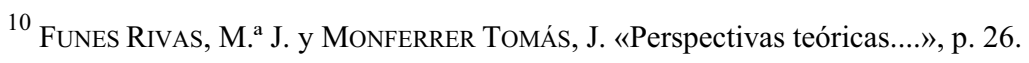

${ }^{11}$ LeÓn CORREA, F. (1982). «El regionalismo leonés en la Segunda República a través de la prensa: El Diario de León». Estudios Humanísticos, pp. 71-84. También: PalomareS, J. M. (1985). «Aproximación al regionalismo castellano durante la Segunda República». Investigaciones Históricas, pp. 267-294. 


\section{b. La Alianza Regional de Castilla y León.}

Teniendo en cuenta estos precedentes encontramos en la Transición un regionalismo conservador representado por la Alianza Regional de Castilla y León, que se caracterizó por la defensa de la unidad de España, pero que ante las peticiones autonómicas catalanas y vascas pidió una autonomía similar, es decir, de nuevo otro regionalismo movilizará al de Castilla y León. De hecho la mayoría de sus miembros procedían de las instituciones franquistas o pertenecían a ámbitos intelectuales. Esta Alianza se fundó en diciembre de 1975, con declaraciones contra el mito del centralismo castellano, por el cual Castilla habría impuesto su cultura a toda España ${ }^{12}$.

Uno de los presidentes de la Alianza fue Alfonso Prieto Prieto, profesor de Derecho que debido a su estancia en Barcelona conocía el problema del regionalismo de forma directa. Coincidió en el estudio de este tema con su homólogo vallisoletano Gonzalo Martín Díaz, con el que estaba de acuerdo en que el proceso autonómico era imparable y el temor de ambos era que la autonomía solo se concediera a Cataluña y al País Vasco. Así su tesis, también defendida por la Alianza, será la implantación de la autonomía en todas las regiones, es decir, propugnaban un regionalismo defensivo ${ }^{13}$. Además, la Alianza esgrimió argumentos económicos para defender la autonomía de Castilla y León, como: “[...] los conciertos económicos navarros y alaveses que pretendían extender a Castilla"14.

\section{c. El Instituto Regional Castellano-Leonés.}

Las formaciones de la izquierda participaron en el regionalismo a través del Instituto Regional Castellano-Leonés -vinculado inicialmente a la Junta Democrática Regional Castellano-Leonesa $-{ }^{15}$. Los presupuestos ideológicos de dicho Instituto estaban basados en la creación de la "conciencia histórica" de Castilla y León, y la crítica del subdesarrollo de esta región, que para ellos había sido causado por la emigración y una explotación de los recursos que sólo

12 Díez Llamas, J. D. (1982). Proceso Autonómico Leonés. León: Grupo Autonómico Leonés, pp. 25-27.

${ }^{13}$ Entrevista realizada a Alfonso Prieto Prieto el 9 de julio del 2003. Se presentó en las listas de la Alianza Socialista Democrática al Senado en 1977 y posteriormente militó en Alianza Popular.

14 CARAsa, P. (coord.). (2003). La memoria histórica de Castilla y León. Historiografia castellana en los siglos XIXY XX. Salamanca: Junta de Castilla y León, p. 568.

${ }^{15}$ Ibídem, p. 568. 
benefició a las clases acaudaladas. Por tanto, consideraban necesario revitalizar económicamente Castilla y León, para lo que este Instituto apoyaba todo tipo de estudios.

\section{d. Las estrategias de movilización de ambas formaciones regionalistas.}

La diferencia más destacable de ambas asociaciones estuvo en sus miembros, porque si los pertenecientes a la Alianza se hallaron, en su mayor parte, relacionados con la política franquista, los del Instituto representaban a los grupos de la oposición democrática. Este último en enero de 1976 publicó sus postulados ideológicos, en los que consideraban a Castilla y León como una región histórica y económica, que compartía los problemas de la emigración, marginación y rentas bajas. Además se propusieron: “[...] recoger un espíritu de conciencia regional que en estos momentos existe en León y Castilla". Por eso decidieron realizar un encuentro en Villalar de los Comuneros el 24 de abril como "[...] fecha memorable en la historia de Castilla y León""16.

El 18 de febrero de 1976 se reunieron en Tordesillas los representantes políticos franquistas de las provincias de Castilla la Vieja y León para tratar de la constitución de la ARCL. Estos profundizaron en temas como los conciertos económicos y la conciencia regional. Al mismo tiempo, acordaron que la Alianza no sería una asociación política, excepto cuando se hablase del tema de la regionalización, lo cual era una contradicción evidente, no solo porque todos eran políticos, sino porque utilizaban políticamente el tema regional ${ }^{17}$.

La fundación de estas asociaciones no debe hacernos pensar que el tema regional o autonómico se constituyó en el fundamental de la Transición leonesa, sino que las élites intelectuales presagiaron que se trataría de uno de los cruciales de la futura democracia. Tampoco debemos olvidar la falta de libertades de ese momento que se traducía en la ausencia de canales de representación política, por lo que no debe extrañar que, tanto la izquierda como la derecha, utilizaran el problema regional para plantear cuestiones claramente políticas.

${ }^{16}$ Diario de León, 13 y 18 de enero de 1976 y Hoja del Lunes, 19 de enero de 1976. Estos datos son buena muestra de los inicios titubeantes de esta experiencia, ya que dicho encuentro en Villalar sería posteriormente el 23 de abril. Pero, consiguieron fijar una fecha que sería utilizada años después como día de la comunidad autónoma.

${ }^{17}$ Diario de León, 18 de febrero de 1976. 


\section{LAS MOVILIZACIONES Y FORMACIONES ESTUDIANTILES. \\ a. Las instituciones educativas en la provincia de León.}

En León, a pesar de que durante el siglo XX hubo unas altas tasas de escolarización infantil, las enseñanzas media y superior eran de una magnitud inferior. Así en esta provincia se crearon varios centros universitarios dependientes del distrito universitario de Oviedo. En el período objeto de estudio se encontraban ubicadas en León la Facultad de Veterinaria -que acogía los estudios de Biología-, el Colegio Universitario de Filosofía y Letras -que integraba también a Derecho- y diversas escuelas universitarias como la de Formación del Profesorado, de Ingeniería Técnica Agraria, Comercio, Empresariales y Minas.

\section{b. Las características del movimiento estudiantil español.}

El movimiento estudiantil español se diferenció de sus homólogos europeos en que fue protagonizado por la izquierda democrática encabezada por el PCE, al contrario que en el resto de Europa donde surgió contra los partidos parlamentarios de izquierdas, lo que se debió a la existencia de la dictadura franquista ${ }^{18}$. De esta manera "[...] predominaron las prioridades derivadas de la lucha contra la dictadura respecto de las planteadas por un desarrollo anticapitalista y contracultural"19.

El movimiento estudiantil fue uno de los pilares del antifranquismo, al luchar por las libertades y un cambio social y político. Así los estudiantes participaron en diversos conflictos: por la amnistía, en relación con el movimiento ciudadano, en solidaridad con las luchas obreras o en las jornadas de lucha. Esto muestra que las universidades españolas se convirtieron durante la dictadura en un espacio político, uno de cuyos rasgos característicos fue la realización de asambleas como "[...] método de elaboración, decisión y lucha" ${ }^{20}$. Éstas requerían una preparación concienzuda y una práctica arriesgada por parte de dirigentes enérgicos, pues

${ }^{18}$ CAMARERo GonzÁlez, Arturo. (1981). «Características generales, objetivos y adversarios del movimiento estudiantil madrileño bajo el franquismo (1)». Revista Internacional de Sociología, p. 419.

${ }^{19}$ CAMARero GonZÁlez, Arturo. (1981). «Características generales, objetivos y adversarios del movimiento estudiantil madrileño bajo el franquismo (1)». Revista Internacional de Sociología, p. 438.

${ }^{20}$ RomÁn, P.; FerRI, J. (2002). Los movimientos sociales. Conciencia y acción de una sociedad politizada. Consejo de la Juventud, Col. CEJOTA-E, (publicado en http://www.cje.es/publicaciones.nsf/ef2e05c02233e9fdc125692b00480008/edb9b71aa8fa67c7c1256b 50003d7291/\$FILE/Movsoc.pdf) 
tenían enfrente a las autoridades académicas y a las fuerzas de la policía ${ }^{21}$. De idéntica forma constituyeron comités de huelga, consejos o comisiones. También utilizaron formas de información alternativas como panfletos, carteles o boletines. Asimismo emplearon las formas de protesta clásica como los mítines, manifestaciones, barricadas, sentadas y el boicot a los exámenes y a las autoridades académicas. Sin embargo, durante la Transición, la política pasó a tener como espacio la calle, debido a que en ella tuvieron lugar las movilizaciones propugnadas por los movimientos sociales.

\section{c. Las acciones desarrolladas por los estudiantes leoneses.}

La tipología de actos realizados por el estudiantado leonés consistió en:

a. Los conflictos corporativos, impulsados para lograr segundos ciclos en facultades, clases prácticas, infraestructuras adecuadas y mejores planes de estudio.

b. Los conflictos antiselectivos: contra el decreto de cuatro convocatorias, la subida de las tasas académicas, el establecimiento de númerus clausus o la supresión de los exámenes de febrero y de los alumnos libres.

c. Las actuaciones a favor de la reforma institucional de la universidad basadas en la lucha por la autonomía, gestión democrática, elección democrática de decanos y rectores ${ }^{22}$.

d. Movilizaciones con finalidad política.

Según esta clasificación la manifestación celebrada en León tras los sucesos de Vitoria de marzo de 1976 cabría incluirla en el último apartado. Sus organizadores fueron Carmen Carlón, como delegada de centro de Veterinaria, y Javier Muñiz, que era su homólogo en Derecho. Dicha marcha comenzó tras una asamblea realizada en Veterinaria, centrada en la merma de la autonomía de los centros universitarios y la represión que tuvo lugar en Vitoria. A causa de esto decidieron realizar una manifestación con el grito de "violencia no" en la que no se produjeron incidentes $^{23}$. En enero de 1976 se había celebrado una asamblea en la Facultad de Veterinaria, probablemente se trató de la primera importante, pues hubo representantes de la empresa eléctrica Standard que "una vez que expusieron sus

21 Camarero GonzÁlez, Arturo. (1982). «La expansión del movimiento estudiantil en Madrid. Formas de movilización y organización. Solidaridad con los estudiantes (1)». Revista Internacional de Sociología, p. 369.

22 RomÁn, Paloma; FERRI, Jaime. Los movimientos sociales...

${ }^{23}$ La Hora Leonesa, 7 de marzo de 1976. 
problemas se marcharon", lo que nos muestra la vinculación con el movimiento obrero, debido a que estos trabajadores se encontraban en plena negociación de su convenio colectivo ${ }^{24}$.

Según Benigno Castro, el movimiento estudiantil leonés estuvo constituido por las "facciones o agrupaciones de juventudes de todo tipo de organizaciones", que estaban representadas en los centros educativos. Había una mayor actividad en el Colegio Universitario y la Facultad de Veterinaria, en cuyo vestíbulo tuvieron lugar un destacado número de las asambleas, al contrario que en las escuelas de Minas y Comercio. La mayoría de las organizaciones eran informales, pues al ser ilegales no tenían una sede ni una estructura, no obstante estaban en contacto con sus direcciones estatales. Lo destacable fueron las dimensiones y la diversificación de este movimiento, si tenemos en cuenta el tamaño de la ciudad de León y la inexistencia de una Universidad ${ }^{25}$.

También se produjeron acciones como huelgas o comunicados, así en la facultad de Filosofía y Letras, el cuatro de mayo de 1976 se convocó un paro en protesta por las cuatro convocatorias de exámenes. Además en septiembre del mismo año escribieron una nota los alumnos de tercero de Biología para protestar por la subida de las tasas académicas, a la vez que pedían una Universidad "científica y democrática" para León ${ }^{26}$. El dos de octubre de 1976 se produjo una manifestación autorizada de los estudiantes leoneses contra la subida de las tasas, por la autonomía universitaria, gestión democrática, enseñanza gratuita y una Universidad para León. Dicha marcha fue disuelta por las fuerzas de orden público: “[...] al salirse ésta de los cauces establecidos". Abrieron la manifestación alrededor de 700 personas, pero acabaron más de 1.500 -según Diario de León-, no en vano era la primera permitida en León en la Transición. Al llegar a la Glorieta de Guzmán se pronunciaron gritos contra las fuerzas del orden y al enfilar el Paseo de la Facultad llegaron efectivos de la policía que cargaron contra los manifestantes y les lanzaron botes de humo. También fueron tratados violentamente algunos representantes de la prensa. Para impedir cualquier intento de reagruparse de los manifestantes en la Plaza de San Marcelo la policía utilizó balas de goma.

${ }^{24}$ Facultad de Veterinaria. Libros de Actas de la Facultad de Veterinaria de León. Acta del 20 de enero de 1976 y Diario de León, 16 de enero de 1976.

${ }^{25}$ Entrevista realizada a Benigno Castro Martínez el 17 de junio del 2003. Secretario general de las Juventudes Socialistas de León durante 1976.

${ }^{26}$ La Hora Leonesa, 4 de mayo y 5 de septiembre de 1976. 
A la cabeza de la manifestación se encontraba uno de los líderes de la huelga de la construcción. Este conflicto, iniciado a finales de agosto, pretendía la obtención de un convenio colectivo para los trabajadores de la construcción de la provincia. Cuando se produjo esta marcha, la huelga estaba a punto de finalizar, debido al acuerdo entre las partes implicadas. Diario de León publicó el cinco de octubre una nota de Coordinación Democrática sobre esta marcha, en la cual consideraban que la violencia de las fuerzas del orden restaba credibilidad al Gobierno, respecto a su voluntad democratizadora y dificultaba sus relaciones con las fuerzas democráticas ${ }^{27}$.

El 26 de enero de 1977 se celebró una asamblea en el Colegio Universitario, en la que analizaron los asesinatos de los abogados laboralistas de la calle Atocha en Madrid -el 24 de enero de 1977-. Los reunidos mostraron su repulsa y dolor por estos hechos y exigieron una decidida acción al Gobierno para encontrar a los culpables. A causa de esto se produjo una manifestación desde la Facultad de Veterinaria $^{28}$.

En la categoría de conflictos corporativos cabría englobar la huelga de los alumnos de primero y segundo de la Escuela de Ingeniería Agrícola, que iniciaron a mediados de febrero de 1977, en protesta por la introducción de un nuevo plan de estudios, a los que se unió el alumnado de tercero el 16 de febrero, después de decidirlo en asamblea. Así crearon una comisión permanente encargada de coordinarse en el ámbito nacional con las Escuelas Técnicas, y en la provincia con los peritos agrícolas ${ }^{29}$.

Del mismo tipo fue el paro de los estudiantes de Graduado Social, que decidieron en una asamblea el 21 de febrero de 1977, para exigir que sus estudios fuesen equiparados a los correspondientes al primer ciclo de enseñanzas universitarias, aparte de pedir que se iniciase la implantación de una segunda fase de dos años, lo que equivaldría a una licenciatura universitaria. Reanudaron la actividad académica el 28 de marzo, después de permanecer 35 días en paro. Pero esta reincorporación no zanjó el problema, ya que cinco de las 12 escuelas del país continuaron $\sin$ actividad $^{30}$. También podríamos considerar como conflicto corporativo la sentada que realizaron una cincuentena de alumnos de la Escuela de

\footnotetext{
${ }^{27}$ Diario de León, 2, 3 y 5 de octubre de 1976.

${ }^{28}$ La Hora Leonesa, 26 de enero de 1977.

${ }^{29}$ La Hora Leonesa, 16 de febrero de 1977.

${ }^{30}$ La Hora Leonesa, 23 de febrero y 1 de abril de 1977.
} 
Empresariales el 15 de abril de 1977, delante de la Escuela de Comercio, para mostrar que se encontraban en paro desde el día anterior. Sus demandas se basaban en que se les concediera el paso al segundo ciclo universitario y el plan de unificación de Escuelas y Facultades de Ciencias Empresariales ${ }^{31}$.

Sin embargo se trató de un conflicto antiselectivo la huelga que tuvo lugar en la Escuela Universitaria de Ingeniería Técnica Minera, iniciada por los alumnos en febrero de 1977 en contra de la Orden Ministerial del 16 de diciembre de 1976, pues consideraban que establecería una formación deficitaria. Un claro contenido político tuvo el encierro que el 14 de mayo abandonaron algunos estudiantes de la Facultad de Veterinaria, y que habían realizado en protesta por la represión de la campaña proamnistía ${ }^{32}$.

No obstante, el hecho en el que se percibió la capacidad de movilización del movimiento estudiantil leonés, por causas políticas, fue la huelga general del 12 de noviembre de 1976. Esa fecha la Coordinadora de Organizaciones Sindicales convocó una jornada de lucha para mostrar al Gobierno de Adolfo Suárez la disposición de la oposición para movilizarse. De esta forma se trató de la “[...] mayor protesta laboral desde los tiempos de la República" "33, con una motivación claramente política. Para Rodolfo Martín Villa fue una: “[...] huelga para desafiar la autoridad del Gobierno, no era una huelga que tuviera presentes reivindicaciones laborales" ${ }^{34}$.

Desde el movimiento estudiantil participaron en la huelga las facultades de Veterinaria y Biológicas, la Escuela de Empresariales y el Instituto Padre Isla, con un paro cercano a los 2.500 estudiantes. Hubo una manifestación a primeras horas de la mañana de aproximadamente 150 personas -según Diario de León- en su mayoría estudiantes que fueron dispersados. Los estudiantes universitarios pararon en su totalidad y realizaron una asamblea en la Facultad de Veterinaria con cientos de alumnos ${ }^{35}$. La publicación del PCE, Avance, profundizó en la movilización

${ }^{31}$ La Hora Leonesa, 16 de abril de 1977.

${ }^{32}$ La Hora Leonesa, 26 de febrero, 16 de abril y 15 de mayo de 1977.

33 PÉREz, J. A. (2001). Los años del acero. La transformación del mundo laboral en el área industrial del Gran Bilbao [1958-1977]. Trabajadores, convenios y conflictos. Madrid: Biblioteca Nueva, p. 402.

34 Entrevista realizada a Rodolfo Martín Villa el 11 de marzo del 2004. Ministro en el $2^{\text {o }}$ Gobierno de Arias Navarro de Relaciones Laborales y en el $1^{\circ}$ de Adolfo Suárez de Gobernación, además de en otros posteriores de la UCD.

${ }^{35}$ La Hora Leonesa y Diario de León, 13 de noviembre de 1976. 
estudiantil, al reseñar las asambleas y paros en algunos cursos de Derecho, la Escuela de Formación de Profesorado de EGB y los Institutos Juan del Enzina y Padre Isla.

Por añadidura fueron detenidos dos alumnos de Derecho -probablemente se trató de los socialistas Juan Díez López y Antonio Villa- el día 10, por eso paró el turno de mañana de Derecho y se leyó un escrito de protesta en Radio Popular. Este hecho motivó la asamblea en Veterinaria y la manifestación antes reseñadas. En algunos institutos la policía intervino contra los estudiantes que no querían entrar en sus clases, e incluso fue desalojado un grupo de alumnas del Instituto Legio VII que se había refugiado en la basílica de San Isidoro ${ }^{36}$.

\section{LA DEMOCRACIA EN LOS BARRIOS: LAS ASOCIACIONES DE VECINOS LEONESAS.}

\section{a. Características de las asociaciones de vecinos.}

Las asociaciones de vecinos españolas, aunque surgieron en la etapa final del franquismo, alcanzaron su culmen durante la Transición. Estas organizaciones al partir de problemas urbanos produjeron "[...] cambios cualitativos en el sistema urbano, la cultura local y las instituciones políticas" ${ }^{, 37}$, por lo que se enfrentaron a los grupos sociales beneficiados por el crecimiento incontrolado de las ciudades. Sus miembros, pese a que en su mayoría eran trabajadores manuales, englobaban también a representantes de los grupos profesionales ${ }^{38}$.

Estos movimientos de protesta urbana surgieron en torno a tres temas:

1. "Las demandas centradas en el consumo colectivo, esto es, los bienes y servicios directa o indirectamente proporcionados por el Estado.

2. La defensa de la identidad cultural asociada con un territorio concreto y organizada alrededor del mismo.

3. La movilización política en relación con el gobierno local"39.

${ }^{36}$ PCE León. «Jornada de lucha del día doce. Las cuentas claras» en Avance. Órgano Provincial del PCE León, 1, (1 diciembre 1976). Archivo personal de Víctor-Manuel Bayón García.

${ }^{37}$ CASTELls, M. (1986). La ciudad y las masas. Sociología de los movimientos sociales urbanos. Madrid: Alianza Editorial, p. 375.

${ }^{38}$ Ibidem, p. 299.

${ }^{39}$ Ibidem, p. 23. Cursiva del autor. 
La tipología de las reivindicaciones comprendía las defensivas, como las que pretendían evitar los efectos perniciosos de la urbanización de los barrios, o las ofensivas que exigían la remodelación de los edificios a favor de residentes, mientras que las demandas más avanzadas pasaban por la reforma institucional, como por ejemplo la participación en el gobierno local ${ }^{40}$.

\section{b. El nacimiento de las asociaciones de vecinos leonesas.}

Las asociaciones organizadas por la Acción Católica propugnaron la creación de estos grupos en los barrios. Así la HOAC de la diócesis de León, alentó el nacimiento en 1970 de la primera asociación de vecinos de la provincia. Estaba establecida en el barrio de Pinilla de la capital de la provincia, y encabezada por José Luis Ropero, que en 1968 era el presidente de la HOAC de la diócesis leonesa $^{41}$. Este barrio se caracterizaba por ser de nueva creación, predominando los trabajadores recién llegados del mundo rural, por lo que sus problemas eran de infraestructuras - mejora de calles y alumbrado público- y falta de puestos de escolarización. Sus logros incluyeron la creación de la parroquia, un colegio y la pavimentación de calles.

A esta asociación se sumaron posteriormente - gracias también a los hoacistasla creada en el Ejido, la perteneciente a Mariano Andrés, y por último la establecida en San Mamés, todas ellas en la ciudad, mientras en la provincia surgieron en Trobajo del Camino y Villabalter. A su vez formaron una Federación de Asociaciones de Vecinos que tuvo una vida efímera. Asimismo el sacerdote Francisco Beltrán, consiliario de la HOAC en las diócesis de León y Astorga, promovió la asociación del barrio de Los Olivares en Ponferrada, que en numerosos casos encubrió reuniones de la oposición antifranquista berciana ${ }^{42}$.

${ }^{40}$ Ibidem, p. 314.

41 Delegado Provincial De La Organización Sindical, «Informe de la Hoac, Joc y Voc en León», León, noviembre 1968. Fondo Sindicatos. Delegación. Legajo 15. Archivo Histórico Provincial de León.

42 Berzal De La Rosa. E. (1999). Del Nacionalcatolicismo a la lucha antifranquista. La HOAC de Castilla y León entre 1946 y 1975. Tesis doctoral inédita. Universidad de Valladolid. Puede ser consultada en http://cervantesvirtual.com/FichaObra.html?Ref=7784. pp. 609-611 y 674. Aunque el autor las sitúa en Trepalio del Camino y Villavaquer ambas poblaciones no existen. 


\section{c. $\quad$ Su reorganización durante la Transición en León.}

A pesar de los logros conseguidos por las asociaciones vecinales, las dificultades con que se encontraron por parte de las autoridades franquistas propiciaron que entrasen en una dinámica de politización que se agudizó en la primera fase de la Transición. Así: "[...] el movimiento vecinal constituyó una antesala hacia la conquista de las libertades, una especie de escuela de democracia"43. En León sólo subsistió desde la etapa precedente hasta la Transición la asociación vecinal de "León Típico"44.

A finales de julio de 1976 se tramitó la aprobación de la asociación de Vecinos de S. Francisco de la Vega, San Antonio de Padua y la Anunciación, para lo que se reunió su junta directiva provisional el día 30 con el objetivo de formalizar sus estatutos. Sus dirigentes se preocuparon por solucionar problemas como el deficiente asfaltado, la escasa señalización, falta de guarderías y ausencia de bibliotecas entre otros ${ }^{45}$. El uno de diciembre quedó legalmente constituida la asociación de vecinos de San Claudio. La asociación del barrio del Crucero puso a la venta un almanaque para 1977, que trataba los problemas sociales y urbanísticos del barrio, y pedía la solidaridad de los vecinos. En marzo de 1977 se encontraban con los trámites de legalización avanzados las asociaciones vecinales de El Ejido, San Mamés, Ventas-Inmaculada-Asunción y el Crucero ${ }^{46}$. Sin embargo, el 21 de ese mes el Gobierno Civil les devolvió la documentación con el pretexto de defectos jurídicos y les advirtió de que no podían realizar actividades, ni actos públicos. Estas asociaciones constituyeron una "Coordinadora" de Asociaciones de Vecinos que a finales de marzo visitó al gobernador civil para conocer los errores de la documentación. La permanencia en la ilegalidad de muchas asociaciones vecinales no fue un hecho exclusivo de León, pues sucedió en toda España. Finalmente la asociación de vecinos "León Típico" en abril de 1977 editó un boletín informativo que destacó por ser el primero de este tipo ${ }^{47}$.

${ }^{43}$ FANDIÑo PÉREZ, R. G. (2000) «Del suburbio a la lucha por la democracia. Una perspectiva histórica del movimiento ciudadano» en Navajas Zubeldia, C. (ed.). Actas del II Simposio de Historia Actual. Logroño: Instituto de Estudios Riojanos.

${ }^{44}$ Concejo, abril de 1977.

${ }^{45}$ La Hora Leonesa, 31 de julio de 1976.

${ }^{46}$ Diario de León, 8 de diciembre de 1976 y La Hora Leonesa, 1 de marzo de 1977.

${ }^{47}$ Concejo, marzo, abril y mayo de 1977. 


\section{LA TRANSICIÓN Y EL FEMINISMO EN LEÓN. \\ a. Las diferentes visiones del feminismo.}

En la segunda mitad del siglo XX se consolidaron dos corrientes feministas: liberal y radical. El feminismo liberal reconocía que las mujeres eran discriminadas a causa de su género, pero entendía este hecho como algo transitorio y que era cuestión de tiempo el que se lograse una plena igualdad. Frente a éste, surgió el feminismo radical, el cual alentó la formación de los "grupos de surgimiento de la conciencia" (consciousness raising groups) ${ }^{48}$. Eran reuniones de mujeres que analizaban sus experiencias personales, como la discriminación en el trabajo asalariado, la ausencia de placer sexual o la asignación de ciertos papeles femeninos en la política -como servir el café a los compañeros o pasar a máquina sus manifiestos. Experiencias que se observaron influidas por el poder político patriarcal y no meramente resultado de sus relaciones personales.

A diferencia del feminismo que incidía en campañas a favor de los derechos de las mujeres, el radical inaugura la crítica y la denuncia contra el patriarcado o sociedad de dominio masculino. Este malestar de las mujeres debido a la situación que estaban descubriendo se unió en España a un marco político carente de libertades, represivo y de ausencia de derechos, lo que se incrementaba en el caso de las mujeres. De esta forma "[...] se fueron formando los grupos embrionarios de un feminismo que comenzaría a tomar cuerpo en $1975^{\prime 49}$. Tomando como punto de partida estas asambleas, las mujeres comenzaron a movilizarse al reclamar igualdad ante la ley, derechos políticos y laborales. Más tarde se añadieron el derecho a una sexualidad libre, al control de la natalidad y al aborto, la ley de matrimonio civil y la ley de divorcio ${ }^{50}$.

\section{b. Los inicios de la Asociación Leonesa de Mujeres Flora Tristán.}

La situación de la mujer española a lo largo de la dictadura franquista fue difícil al carecer de todo tipo de derechos, en mayor medida de la ausencia que padecieron los hombres, al estar subordinadas a su padre, para al casarse pasar a depender de su marido. Esto sin mencionar el escaso reconocimiento al trabajo realizado, tanto en los salarios, como en los derechos laborales. Ambas

48 ROMÁN, P., FERRI, J, Los movimientos sociales...

49 LÓPEZ-ACCOTTO, A. I. (1999). «Las mujeres en la transición política española» en NuÑo GómEZ, Laura (coord.). Mujeres: de lo privado a lo público. Madrid: Tecnos, p. 116.

${ }^{50}$ Ibidem, p. 113. 
problemáticas confluyeron en la formación del movimiento feminista en la década de los sesenta, que irreversiblemente se encontró -debido al contexto dictatorialvinculado a la oposición democrática.

El desarrollo del feminismo se produjo durante la Transición, debido a la eclosión democrática que condujo al nacimiento de un gran número de organizaciones caracterizadas por su "fragmentación, viveza y caducidad" 51 . La vinculación entre algunos de estos grupos y la oposición se percibe en la relación entre el Movimiento Democrático de Mujeres y el PCE, o entre la Asociación Democrática de la Mujer y el Partido del Trabajo de España. En León desde 1975 comenzó a reunirse un grupo de mujeres caracterizadas por su ideología de izquierdas, que habían participado en la creación del CCAN ${ }^{52}$. Su motivación principal era sacar a la luz la problemática concreta de las mujeres, ya que hasta ese momento los grupos opositores basaban sus luchas en criterios patriarcales, es decir, la consecución de la democracia no llevaba implícito el reconocimiento de derechos de las mujeres, ni la igualdad legal plena, lo que sí eran objetivos del movimiento feminista. Su labor de concienciación de la sociedad en estos aspectos fue fundamental.

Como expone Olga Castrillo las mujeres “[...] participaban por igual en los movimientos de izquierdas, movimientos de protesta, en los movimientos democráticos, en las de lucha, luego se veía, sin embargo, que se seguía permaneciendo en un papel secundario" "53. Hasta 1977 estas leonesas realizaron una serie de debates en los que analizaron la situación legal de las mujeres o cuestiones como la revolución sexual, es decir, de esta forma crearon grupos de autoconciencia. Tras estas reuniones decidieron no adscribirse a ningún colectivo concreto dentro del movimiento feminista, debido a su heterogeneidad.

Con respecto a las mujeres que pertenecían a partidos políticos, y se habían incorporado, no se permitió que hicieran una política de partido en la asociación, aunque se les permitió la doble militancia. Esta medida es preciso inscribirla dentro

51 Larrumbe, M. á. (2002). Una inmensa minoría. Influencia y feminismo en la Transición. Zaragoza: Prensas Universitarias de Zaragoza, , p. 139, 153 y 162.

52 Sobre este Club consultar: CCAN. (1992). 20 años, un quinto de centenario. León: Gráficas Celarayn. Se trataba del Club Cultural y de Amigos de la Naturaleza que había sido fundado en 1973 por militantes de izquierda con la finalidad de realizar todo tipo de actividades políticas y culturales contra la dictadura.

53 Entrevista a Olga Castrillo realizada el 16 de diciembre de 2003. Fundadora de la Asociación Leonesa de Mujeres Flora Tristán en 1977. 
del "[...] debate entre las partidarias de la doble militancia - política y feminista- y las defensoras de la militancia única feminista" ${ }^{\text {"54 }}$. Finalmente en 1977 se legalizó y adoptó como nombre el de Asociación Leonesa de Mujeres Flora Tristán ${ }^{55}$. Con presupuestos distintos al de la asociación Flora Tristán se constituyó en León la Asociación Democrática de Mujeres que se encontraba vinculada al PTE. Dicho partido no pudo presentarse a las elecciones del 15 de junio de 1977, puesto que no había sido legalizado. Aún así formó la candidatura denominada Frente Democrático de Izquierdas, que también apoyó la Asociación Democrática de Mujeres de León.

\section{CONCLUSIONES.}

El protagonismo de los movimientos sociales en la etapa inicial de la Transición es incuestionable, como creemos haber demostrado para el caso leonés en la presente investigación. De esta forma hemos rebatido la idea que considera a esta región como una zona tranquila en la que apenas hubo reivindicaciones sociales tanto durante la dictadura como posteriormente. Sin embargo, como se ha reseñado, surgió un fuerte movimiento estudiantil, pese a estar englobada la provincia en un distrito universitario más amplio, o unas combativas asociaciones vecinales que tuvieron su precedente durante la dictadura. Aunque menos importantes en cuanto a su militancia, los diversos grupos regionalistas anticiparon las vertientes de un problema que tendría lugar posteriormente. Mientras que las asociaciones feministas provocaron una importante transformación ideológica de la sociedad leonesa.

Si los partidos políticos impulsaron la democracia parlamentaria, los reseñados movimientos sociales propiciaron, en el período estudiado, la transformación democrática de la sociedad leonesa.

\section{BIBLIOGRAFÍA CITADA:}

A. L. M. Flora TRISTÁn. (1986). ¿Qué es el Feminismo?. Folleto Informativo. León: A. L. M. Flora Tristán.

AdELL ARGILÉS, R. (1994). «Movimientos sociales y contexto político». Leviatán, pp. 113-130.

54 CAPEL MARTínez R. M. ${ }^{\text {a }}$ (2004). «As primeiras eleccións da Transición democrática e a muller». Dezeme, pp. 63-65.

${ }^{55}$ A. L. M. Flora Tristán. (1986). ¿Qué es el Feminismo?. Folleto Informativo. León: A. L. M. Flora Tristán, pp. 13-14. 